\title{
La sociedad paraguaya en Un viento negro de Alcibiades González Delvalle: Estudio analítico
}

\author{
Amr Farag-Allah Ahmed Youssef \\ Investigador de Filología Hispánica \\ amryuosef94@gmail.com
}

Received: March 17, 2020 Accepted: July 9, 2020 Published: October 26, 2020

\section{Resumen:}

El presente trabajo trata el análisis de los aspectos sociales y políticos de Paraguay en Un viento negro. La novela narra los testimonios de 5 víctimas de la dictadura stronista. Pues, el trabajo explica el papel de la novela testimonial en la literatura hispanoamericana y sus características generales.

Palabras clave: testimonio, represión, sociedad, religión

\section{Introducción}

La novela testimonial es uno de los géneros literarios fundamentales en América Latina. Se desarrolla en la literatura hispanoamericana en el siglo XX, ya que la mayoría de los países hispanoamericanos estaban bajo la dictadura y el poder de los gobiernos militares que violan los derechos humanos. En consecuencia, los pueblos estaban sufriendo unas crisis económicas, sociales y políticas. Este género que posee la fórmula común de presentar el material testimonio, cuestionando a nivel social, cultural y político, es perfecto para describir y revelar la situación social hispanoamericana en la época de la represión política y cultural bajo las dictaduras. "La escritura testimonial es el instrumento por el cual grupos marginados emergen en movimiento de postura privada a la de testigo" (Melo, 2005).

Paraguay es uno de los países latinoamericanos que sufrió mucho bajo la dictadura. El 3 de febrero de 1989 el general Andrés Rodríguez anunció la caída del régimen dictatorial en Paraguay después de 35 años de represión. Este anuncio permitió a los escritores y críticos paraguayos 
empezar a emplear sus bolígrafos para describirnos una página negra del libro de la historia humana. Uno de estos escritores es Alcibiades González Delvalle quien publicó muchas obras que revelan los terrores del gobierno dictatorial, entre las cuales se destaca la novela objeto de nuestro estudio, Un viento negro.

Alcibiades González Delvalle es uno de los escritores contemporáneos más talentosos y atrevidos en Paraguay, se conoce por su estilo innovador que sale de los cánones tradicionales de la escritura. A pesar de que el género testimonial existía en América Latina desde los años sesenta, González Delvalle se considera uno de sus fundadores en Paraguay. Por otra parte, se destaca también por su forma diferente en elegir los temas que abordan los asuntos sociales. Además, es uno de los escritores que comparten con sus obras contra la dictadura.

Todos conocemos a Alcibiades González Delvalle, excelente periodista, dramaturgo y escrito..., además de ser, en los tiempos más duros de la dictadura de Stroessner, un hombre combativo y contestatario, no amilanándose ante las persecuciones y las amenazas. Amén de su militancia a favor de la libertad y de los derechos humanos, supo conquistar un destacado espacio en el quehacer artístico y teatral. (Roche, 2012)

González Delvalle conocía bien la vida social y la represión bajo la dictadura, lo que ayudó a escribir una novela testimonial que ganó el premio de Novela Lidia Guanes en 2012 y el Premio Nacional de Literatura en 2013, máxima distinción que puede recibir un escritor nacional.

La novela nos revela todos los aspectos de la sociedad paraguaya bajo la dictadura, especialmente el sentimiento público del sufrimiento bajo la represión política y cultural "Es una novela que reproduce un momento histórico del Paraguay en su lado más atroz y con toda su crueldad, pero va mucho más allá: es una novela sobre la crueldad" (Barco and Alcalá, 1999).

\subsection{La novela testimonial hispanoamericana}

La literatura protesta en general y la novela testimonial en particular son herramientas de los escritores hispanoamericanos en el siglo XX para luchar contra las dictaduras, ofreciendo la cara más realista de la 
dictadura en la novela documental y los aspectos sociales más negativos del mandato del régimen dictatorial. Puesto que, por el control y la represión de las dictaduras de los medios de comunicación, la novela testimonial representa la voz de las clases sociales marginadas de América Latina en aquella época.

La novela testimonial se define según múltiples perspectivas literarias. Por ejemplo, desde el punto de vista de Mirna López: "la novela testimonial es una expresión ideológica de la revolución ya que está intentando declarar los sufrimientos y atropellos cometidos en una nación o pueblo" (López, 2006, p.5). Por su parte, Wiene Van Guyse cree que:

El testimonio se amolda a una ramificación binaria. El primer ramo luce la base del testimonio, a saber, la declaración oral del testigo. Ese testigo generalmente representaba a una víctima de un abuso social o político, que a causa de su analfabetismo no era capaz de poner su miseria sobre el tapete. Por eso invocaba la ayuda de un erudito que se cargaba de la grabación del relato. (Van Guyse, 2012, p. 8)

Según las definiciones anteriores, se puede observar que el género testimonial está basado en dos factores principales: primero, la existencia del gobierno autoritario, especialmente el militar; segundo, la existencia de los marginados los que sufren la represión e injusticia de este gobierno autoritario. Por consiguiente, la novela testimonial es la voz de protesta de los marginados a nivel social, cultural y político.

\subsubsection{El surgimiento de la novela testimonial}

La escritura testimonial existía en la literatura hispanoamericana desde el siglo XVI con la presencia de las crónicas que describen los detallas de la conquista española a los territorios mexicanos: "Aunque ha recibido un éxito enorme en los últimos treinta años, la literatura testimonial latinoamericana ya disfrutaba de cierta popularidad en el siglo XVI" (Van Guyse, 2012, p. 8). Sin embargo, otros investigadores como Judit Gerendas opinan que el testimonio es más antiguo en la literatura latinoamericana y los productos literarios indígenas marcan el verdadero surgimiento de la escritura testimonial:

La presencia simultánea en el mismo texto de lo épico, lo narrativo, lo documental, lo teórico, es también una constante de nuestra literatura, no solamente de desde la producción de las crónicas, sino también literaria indígena misma. (Gerendas, 1992, p. 8) 
El reconocimiento de oficial de la novela testimonial tardó a principios de los años setenta, específicamente después de la reunión de jurados y organizadores de Casa de las Américas en el 4 de febrero de 1969 para proponer cambios y sugerencias producidas por la reflexión colectiva que determina la inclusión del nuevo género. Los críticos literarios participados en la reúnen como David William Foster, Ángel Rama, Julio Ortega, Carlos Rincón y José Luis González, marcaron el surgimiento del nuevo género con la publicación de Biografía de un cimarrón (1966) del escritor cubano Miguel Barent: "Durante la década del ochenta la reflexión teórica sobre el testimonio se localiza en los trabajos de Renato Prada Oropeza, Héctor García Cavallari, Víctor Casaus y Miguel Barnet, fundamentalmente" (Goicochea, 2000, p. 8).

\subsubsection{Características de la novela testimonial}

La narrativa testimonial tiene dos tipos en general: la biografía, es la narración de los relatos de otros protagonistas, como la novela de Barent y también como la novela objeto de nuestro trabajo Un viento negro. La biografía se divide en dos clasificaciones: biografía novelada que narra los hechos de la vida de un personaje, pero no necesariamente es siempre fiel a la realidad y biografía ficticia o novela biográfica que consiste en contar la historia de un personaje inventado como si fuera biografía real. El segundo tipo de la narrativa testimonial es la autobiografía, escritura de la vida de sí mismo como en el caso de Un indígena mexicano de Ricardo Pozas y Si me permiten hablar de Moema Viezzer.

Una de las características fundamentales de la novela testimonial es la multitud de las voces narrativas. Aparecen las voces de las personas, en diálogos contextualizados tanto en el espacio como en el tiempo en los que transcurren los acontecimientos, reelaborados por el autor según sus investigaciones, pero al mismo tiempo presentados al modo de un relato ficcional. Del otro lado la voz del narrador se presenta por los testimonios directos obtenidos por el autor a partir de sus investigaciones que se presenta en la misma trama narrativa. Por su parte, el escritor normalmente se compromete a producir un trabajo cooperativo entre él mismo y las voces de los testigos para aclarar la visión del mundo desde el punto de vista del testigo. 
En la mayoría de las novelas testimoniales, el modo de presentación de los personajes y la organización de los acontecimientos están relacionados con el género policial, así, los testigos, incluso los secundarios son descritos desde una perspectiva singular para acercar al lector, y el narrador por su parte ejerce el papel del detective.

\subsection{La novela testimonial paraguaya}

Paraguay es uno de los países que han sufrido mucho bajo el régimen dictatorial. Después de la proclamación de su independencia en 14 mayo de 1811, el país estaba gobernado por una serie de dictadores, desde el primer presidente de la nueva república de Paraguay que fu José Gaspar Rodríguez de Francia -conocido como el supremo- quien mantenía el poder hasta su muerte en 1840 llegando al último gobierno dictatorial de Stroessner. Normalmente este factor se refleja en su literatura, especialmente en los géneros literarios relacionados con la sociedad, como el género testimonial. La novela testimonial estaba en su momento de auge en los años ochenta, pero la continuación de la dictadura paraguaya hasta el año 1989 prohibió a los escritores y creadores paraguayos profundizar en los géneros literarios sociales. La represión contra los escritores y los medios de comunicación los obliga a dejar el país para librar sus bolígrafos. Por eso, se nota que la mayoría de las obras literarias paraguayas relacionadas con el campo social en general, fueron escritas y publicadas en el exilio:

\footnotetext{
Las circunstancias anómalas, a menudo trágicas, de su trayectoria histórica han influido en las modalidades y características de la producción literaria que surge en el ámbito de un espacio unas veces estrecho y hondo, como el que deja la represión a los que permanecen en el país, los que trabajan entre las penumbras de la amenaza, el miedo y la autocensura...En esas condiciones, no es de extrañar que gran parte de la literatura paraguaya se realice en destierro. (Faith, 1985, p. 6)
}

Como es bien sabido, la época del gobierno dictatorial de Stroessner es la más influyera a la vida social paraguaya en el siglo XX. Desde 15 agosto de 1954 hasta 1989 el general Alfredo Stroessner gobernó Paraguay con la ayuda de las fuerzas armadas y el partido Colorado. Stroessner creó un régimen militar autoritario que se llama Stronismo. Se trata de un orden en el que la decisión tiende a ser confinada en el interior del núcleo soberano. Entonces, a principios de los años noventa aparecen las novelas 
históricas que tratan los horribles acontecimientos de esta época. Pero estas novelas tienen el mismo carácter histórico ficcional, como Esta zona está ocupada (1994) de Raquel Saguier, Celda 12 (1991) de Moncho Azuaga y La querida (2008) de Ricardo Miglorisi.

Aquí podemos notar que la sociedad paraguaya tenía las características necesarias para crear novelas documentales de todo tipo. La mayoría de los escritores paraguayos preferían utilizar la novela histórica ficcional para documentar los acontecimientos históricos, políticos y sociales. Según nuestra investigación, nos parece que no hay una novela paraguaya perteneciente al género testimonial. Por eso, se puede decir que la novela objeto de nuestro trabajo, Un viento negro (2012) de Alcibiades González Delvalle, es la primera novela testimonial paraguaya.

\subsubsection{Un Viento Negro}

Un viento negro trata el testimonio de la situación social de las víctimas de la dictadura stronista. En 29 de septiembre de 2012, la obra ganó el Premio de Lidia Guanes de Novela Inédita en su tercera edición. Un año después, en diciembre de 2013, el presidente Paraguayo Horacio Cartes entrega el Permio Nacional de la Literatura a González Delvalle por la misma novela.

En cuanto al escritor de la obra, Alcibiades González Delvalle es un periodista, dramaturgo y novelista paraguayo nacido en Ñemby en 1936. En la década de los años cincuenta y mediados de los sesenta trabajó en varios periódicos, El Independiente, El País y La Tarde. También fue jefe de redacción de la Revista Dialogo y miembro del consejo de Redacción de la Revista Nuestro Tiempo. Fue director del Centro Cultural-Manzana de la Rivera y posteriormente de la Dirección General de Cultura de la Municipalidad de Asunción. En 1967 se incorporó en el diario ABC Color y sigue escribiendo al mismo diario hasta hoy el día.

\section{La situación política}

La novela narra cinco relatos de distintos personajes. En el día del golpe del estado "3 de Febrero 1989"1, los personajes empezaban a recordar los

\footnotetext{
${ }^{1}$ Según Olivier Dabéne, por causa de la crisis económica en los años ochenta, los regímenes políticos de los países latinoamericanos embazaron a convertirse a la democracia. "En otras partes de América Latina, los procesos llamados de transición a
} 
acontecimientos horrorosos que han sufrido en La Pascua Dolorosa en 1976.2 La obra está dividida en cinco capítulos; cada uno narra un relato de los cinco personajes principales de la novela.

\subsection{La represión política en Un Viento Negro}

La represión política es la persecución de un individuo o grupo por motivos políticos. Es una herramienta por medio de la cual las dictaduras contralan al pueblo sin ninguna oposición real. Según Elizabeth Lira, la represión política es: "La utilización del miedo al dolor y a la muerte y el manejo de la capacidad de producir dolor mediante torturas" (Lira, 2004, p. 221). La represión no es solo una cuestión problemática que distingue la dictadura de la democracia, sino que también es una violación de los derechos humanos.

Un viento negro representa la represión contra todas las clases de la sociedad paraguaya, tanto las cultas "estudiantes y sacerdotes" como las de menor nivel de educación "campesinos".

En primer lugar, analizaremos el interés del público por la política. La obra nos explica cómo la gente se convirtió en personas que reivindican el cambio de la situación política paraguaya. El primer capítulo narra los pasos de la transformación de los estudiantes paraguayos tanto en Paraguay como en el extranjero representados por Blas Arzamendia. La obra marca claramente la diferencia entre los estudiantes paraguayos que viven dentro el país y los que tuvieron un espacio fuera de Paraguay, especialmente en Argentina. Se hace una comparación entre el sistema educativo en Paraguay bajo el mandato de Stroessner y el argentino,

\footnotetext{
la democracia no engendraron violencia alguna. Fueron los militares, desacreditados y deseos de dejar en manos civiles la gestión de la crisis económica”. Esto es lo que ocurrió en el caso paraguayo. En el 3 de febrero de 1989, el general Andrés Rodríguez anunció el golpe de estado y la caída del régimen dictatorial en Paraguay. Véase, (Dabéne, 2000, p. 155-156)

${ }^{2}$ En abril de 1976, la Policía política paraguaya desataba una de las más violentas oleadas represivas de su historia en general, conocida históricamente como, La Pascua Dolorosa. La policía descubre la alianza de los campesinos de Las Ligas Agrarias Cristianas y los estudiantes de la OPM. Luego la Policía política pudo capturar a la mayoría de los principales líderes de la (OPM) y también matar al jefe de la organización Juan Carlos Da Costa. Los campesinos tuvieron la gran parte del terror, ocho de ellos fueron ejecutados mediatamente y los arrestos fueron llevados a la cárcel de Abraham Cue. Véase. (Paz, 2014, p. 55).
} 
presentando la Universidad de La Plata como modelo. Mientras que Paraguay es un ámbito silencioso, en la Universidad de la Plata se organizan debates en las aulas y en los pasillos: "Blas hace memoria de su estada en la Argentina bajo el gobierno de Isabel Perón que permitió, voluntariamente o no, una vida universitaria movida, agitada, polémica, muy distinta de la que se lleva en Asunción que es opaca, silenciosa, sin cabida para las discusiones abiertas" (Delvalle, 2012, p.19). El escritor describe el asombro de Blas Arzamendia cuando ha visto los aspectos de la libertad en las aulas de La Universidad de La Plata por primera vez:

A Blas le deslumbra la libertad de opinión en las aulas y fuera de ellas expresada en ardorosas discusiones y en los carteles, afiches, panfletos que evocan la lucha del Che Guevara, de Fidel Castro, de Perón en el exilio que alienta a Montoneros y al Ejército Revolucionario del Pueblo (ERP), cuyos integrantes colman las distintas facultades de la universidad. (Delvalle, 2012, p. 21)

La comparación confirma la existencia de la represión política en las instituciones educativas paraguayas, también se destaca la gran influencia de los estudiantes argentinos y su experiencia en resistir la dictadura sobre sus compañeros paraguayos.

El segundo capítulo y los tres siguientes tratan los relatos de las clases sociales más oprimidas, los campesinos. La novela nos revela que el interés de los campesinos por la política empezó con sus intentos de mejorar la vida de la sociedad rural. Entonces, el objeto principal del establecimiento de las organizaciones campesinas como Las Ligas Agrarias Cristianas ${ }^{3}$ fue económico y social en primer lugar. Según el relato del líder campesino Dionisio Rojas se nota que las discusiones de los campesinos son aladas de las noticias de las tierras agrícolas, el sistema del trabajo que les permitían producir una producción suficiente para el consumo y la comercialización y adoctrinar en la idea de más producción y mejores ganancias.

\footnotetext{
${ }^{3}$ Son unas organizaciones campesinas de Paraguay que fueron establecidas en las décadas del 1960 y 1970, agrupando miles de personas. Hay muchas opiniones sobre el origen de las Ligas en Paraguay. Según Ignacio Telesca, algunos dicen que nacieron de la mano de los curas; otros, que los gestores fueron los sindicalistas y son muy poco que creen que los campesinos, por sí solos, fueran capaces de reunirse, de agruparse, de organizarse (véase Telesca, 2014).
} 
Cuando al cabo de un tiempo se sintieron sólidamente unidos, y buscaban impulsar el crecimiento institucional y económico, implementaron la idea de un almacén de consumo que desde hacía tiempo planeaba en las reuniones. La diferencia de precios en la compraventa de los productos les hizo ver el tamaño del despojo que habían sufrido. (Delvalle, 2012, p. 51)

Las actividades de las organizaciones campesinas eran legales y protegidas por la Constitución. Pero el gobierno emplea todas sus instituciones para destruir esas actividades. Por ejemplo, el testimonio de Raimundo Flores se considera como un intento del gobierno para destruir la idea de las escuelitas:

La aceptación masiva de los campesinos porque sus hijos se eduquen para ser ciudadanos obligó a las autoridades educativas, en colaboración con las comisarías, a reunirse con los padres de familia para hablarles de la importancia de la educación formal, único medio capaz de asegurar el futuro del niño. Sin esa educación, se les dijo, nunca dejarán de ser pobres porque vivirán atados, en el mejor de los casos, a la azada y el machete. (Delvalle, 2012, p. 277)

Desde el punto de vista de González Delvalle, el gobierno estaba en contra de las organizaciones campesinas: "El Gobierno nada quiere saber de los campesinos organizados" (Delvalle, 2012, p.170). Por eso, los campesinos fueron obligados a luchar contra la dictadura para alcanzar sus objetivos sociales, porque en esta etapa descubrieron que este régimen nunca les permitía mejorar su vida. Aquí aparece en la trama de la novela por primera vez, la unión entre los campesinos de Las Ligas Agrarias Cristinas y los estudiantes de la OPM4. Aunque, en los tres primeros capítulos se observa que cada clase tiene sus propios intereses y objetivos. Finalmente, en el cuatro capítulo, los dos grupos se encuentran para luchar contra la dictadura con el fin de mejorar la sociedad paraguaya: "Entre los papeles que Martina amontona debajo del guayabo para quemarlos, encuentra unos apuntes de Raimundo Flores en los que

\footnotetext{
${ }^{4}$ La Organización Político Militar o La Organización Primero de Marzo fue un movimiento guerrillero que se había formado en 1973 por unos estudiantes paraguayos en Argentina que buscaban derrocar al régimen de Stroessner. La OPM creció de forma acelerada desde 1974 cuando reclutó a miembros del Movimiento Independiente en Asunción y a algunos líderes de Las Ligas Agrarias Cristianas en las zonas rurales. Véase, (Contrera, 2018).
} 
expresa su contradicción inicial sobre la OPM" (Delvalle, 2012, p.214). $\mathrm{El}$ autor quiere afirmar que, aunque hay muchas diferencias entre los dos grupos, todas las clases sociales paraguayas deciden unirse contra el régimen dictatorial.

\subsubsection{Tipos de represión}

La represión es organizar la violencia contra el público por parte del gobierno. Por lo tanto, está utilizada para establecer el mandato dictatorial evitando el surgimiento de las nuevas formas de las organizaciones políticas y sociales. La escalada represiva ha venido a raíz del aumento de la protesta social ante las crisis políticas y económicas: "Desde el sesgo de la ciencia política, la represión es una de las posibles acciones reguladoras que los gobiernos adoptan contra los individuos o los grupos que desafían las relaciones existentes de poder" (Calleja, 2006, p. 5).

En los testimonios de Un viento negro, se observa los diferentes tipos de la represión política. El autor pretende mostrar al lector cómo podía el régimen dictatorial paraguayo mantener el poder a lo largo de muchos años.

Una de las herramientas represivas de la dictadura es la educación oficial y el control sobre el sistema educativo. Es uno de los medios represivos tradicionales en todas las dictaduras del mundo:

\footnotetext{
La política educativa tiene dos aspectos que aparecen de manera entrelazada pero que a efectos del análisis es necesario distinguirlos para luego poder integrarlos. Por un lado, está la dimensión represiva en el plano ideológico, que apuntaba a destruir todas aquellas expresiones organizativas que trabajaban en el plano de las ideas. (Cardelli, 2016, p.13)
}

En el cuarto capítulo, el escritor se profundiza en el papel de la educación oficial en la sociedad paraguaya, especialmente en la comunidad de los campesinos. El enfoque principal de la educación oficial es ajeno a las ciencias relacionadas con la comunidad campesina. La educación oficial se concentraba más en mejorar la imagen del dictador y en controlar la mentalidad de los niños y los contenidos curriculares: "El exagerado encumbramiento del dictador por encima de los próceres y de los héroes; 
los libros de lectura cuyas imágenes exhiben una realidad distorsionada de la cotidianeidad campesina" (Delvalle, 2012, p.214).

Por otra parte, la educación oficial se convirtió en una herramienta de propaganda para la dictadura, lo que llevó a los campesinos a establecer las escuelitas: "Es la primera vez que alguien plantea la eventualidad de independizar los estudios primarios que en manos del Gobierno se vuelven un instrumento de propaganda" (Cardelli, 2016, p.13).

Otro medio de represión política utilizado por el gobierno paraguayo es reprimir a las organizaciones sociales tales como Las Ligas Agrarias Cristianas. El objetivo principal de la represión de las organizaciones es obstaculizar y neutralizar la capacidad de lucha de la sociedad. Por lo tanto, la ideología represiva utilizada contra las organizaciones es aislarlas de la sociedad y evitar que sus actividades ganen el apoyo popular. Además, el gobierno tiene miedo de que estas organizaciones puedan mostrar su interés por la política en cualquier momento: "El control social englobaba los mecanismos institucionales con los que la sociedad regulaba la conducta individual y el modo en que esta conducta estandarizada sirve para mantener la organización social" (Cardelli, 2016, p. 7).

La represión de las organizaciones sociales campesinas sucedió en la novela cuando Las Ligas Agrarias decidieron aprovechar unas tierras pertenecientes a la iglesia local para que los campesinos más pobres puedan utilizarlas. Después de las negociaciones con los sacerdotes de la iglesia, se aprobó a dejar las tierras a los campesinos. Las autoridades locales que estaban observando la situación desde el principio no les gustó la actitud de Las Ligas Agrarias. Así, arrestan algunos de sus líderes, aunque la iglesia no tiene ningún inconveniente en dejar las tierras para los campesinos.

El último medio de la represión es el monopolio del poder, lo que se considera una de las estrategias básicas de todas las dictaduras: "Las teorías inspiradas en el Leviathan consideran la violencia como algo inherente a la acción política, puesto que la paz social está garantizada a través del monopolio del uso de la fuerza por parte del Estado". (Cardelli, 2016, p.7). Este medio causó el surgimiento de las organizaciones 
armadas que luchaban contra el gobierno porque con el monopolio del poder por parte del gobierno nunca se permitió a las oportunidades de diálogos democráticos. Un viento negro nos explica que la aparición de las organizaciones armada como la OPM es una de las consecuencias del monopolio del poder. Asimismo, el gobierno controla los resultados de las elecciones: "La oposición tradicional se entretenía con el juego de las elecciones que nunca ganaría porque el Gobierno cargaba los dados y luego los hacía rodar con el acierto basado en la experiencia" (Delvalle, 2012, p. 270).

\subsubsection{Formas de represión}

Las dictaduras siempre utilizan la violencia contra el pueblo para controlarlos y mantener el poder. Alfredo Stroessner creó un régimen militar autoritario llamado Stronismo, se trata de un orden en el que la decisión tendrá que ser confinada en el interior del núcleo soberano:

El estado era el poder supremo de la dicción, el actor más poderoso en la vida cotidiana del país, controlando sin poder ser controlado efectivamente por los ciudadanos, ordenando sin que le pueda dar órdenes, imponiendo sin que se le pueda imponer algo a su vez. (Arditi, 1992, p. 18)

La dictadura impulsó arbitrariamente terribles castigos fuera de la ley, lo que creó un miedo sistemático en la vida normal de los ciudadanos. Durante los 35 años del stronismo, entre 3000 y 4000 personas fueron asesinados debido a sus tácticas de mano dura contra la disidencia. Además, más de 400 personas desaparecieron durante el gobierno de Alfredo Stroessner entre los años 1954 y 1989:

Han pasado casi tres décadas desde que concluyó en Paraguay uno de los regímenes militares más largos y represivos en la historia de Latinoamérica, pero al día de hoy no se ha identificado a uno solo de los más de 400 desaparecidos durante el gobierno de Alfredo Stroessner (1954-1989). (Smink, 2015)

Según los testimonios de los personajes de Un viento negro, se nota que las formas de represión se dividen en dos modos principales: la represión física y la psicológica. A continuación, analizaremos todas las formas de represión en la novela según los testimonios de las víctimas.

\subsubsection{Represión física}


Una de las formas de represión física presentadas en la novela es la desaparición forzada, como en el caso de Reinaldo Benítez, el ex novio de Cristina. Reinaldo despareció y nadie sabía dónde estaba. Luego, apareció el hermano de Reinaldo para informar a Cristina que la Policía de Investigaciones lo había sacado de su domicilio. Tres días después le devuelven muerto, con rastros de haber sido torturado: "Cuando estaba en los preparativos apareció el hermano de Reinaldo con la noticia de que el domingo, en horas de la madrugada, la Policía de Investigaciones lo había sacado de su domicilio. Tres días después le devuelven muerto, con rastros de haber sido torturado." (Delvalle, 2012, p. 125). La causa oficial del fallecimiento fue "edema pulmonar". Este personaje no continúa en la novela, solo presenta como un difunto.

Los asesinados mencionados en la novela no son casos individuales, sino es una manera del gobierno para terminar cualquier intento del pueblo para luchar contra el régimen dictatorial. En el cuarto capítulo de la obra, el autor nos aclara que el régimen dictatorial tenía una banda criminal conocida como la "Triple A" que tiene como misión eliminar a los adversarios políticos del gobierno en el extranjero:

Nuestro crecimiento es también nuestro problema. Necesitamos la presencia de algunos de los compañeros de Corrientes, Buenos Aires y La Plata porque no tenemos la cantidad suficiente de dirigentes que lideren a los nuevos integrados. Además, tenemos que preservarlos de la banda criminal conocida como la "Triple A" que elimina a los enemigos del gobierno. (Delvalle, 2012, p. 251)

El gobierno considera los opositores políticos como enemigos del Estado, así se puede justificar los horrores de la dictadura, sobre todos los asesinatos de los opositores políticos. Un viento negro narra los asesinatos ocurridos en la época stronita en general.

Un claro ejemplo en este sentido es Raimundo Flores, el personaje principal del tercer capítulo. Fue asesinado por las manos de la policía cuando estaba intentado escaparse. Luego, la novela nos describe la escena dramática de la familia de Raimundo cuando encuentran a su cuerpo, mientras tanto la obra nos confirma la indiferencia de las fuerzas oficiales después la acción: "Martina salió desesperada, seguida de sus 
hijos. Pronto encontraron a Raimundo degollado y con un orificio de bala en el pecho, tirado en el yuyal"' (Delvalle, 2012, p. 207).

\subsection{Tipos de tortura.}

En el caso de Paraguay bajo la dictadura, el proceso de la interrogación se convierte en un proceso duro de tortura para sacar las informaciones necesarias de los presos. Un viento negro nos narra los diferentes tipos de tortura utilizados por las autoridades contra los encarcelados.

El primer tipo de tortura es apagar los cigarrillos en los genitales de las víctimas. El autor nos explica que es lo primero que sufren las víctimas en el proceso de interrogación: "Es el inicio de lo que vendrá después en la cámara de torturas. Fuma mucho, y a igual que los demás torturadores, apaga el cigarrillo en los genitales de la víctima, hombre o mujer" (Delvalle, 2012, p. 4).

Luego aparecen otros tipos de la tortura tales como golpear a los presos levantados acerca de la pared en el patio por horas con la orden de no moverse ni un centímetro. Además, el uso de la pileta para hacer una mezcla de los golpes y la sensación de ahogo. Este tipo de tortura es utilizado con Dionisio Rojas. La novela nos confirma el sentimiento horrible de la víctima: "Rogó en un momento de lucidez que un certero golpe acabase con sus penalidades" (Delvalle, 2012, p. 37).

El primer capítulo termina con la muerte de Blas Arzamendia durante el proceso de la interrogación. Aquí, observamos que Blas sufrió todos los tipos de tortura arriba citados:

\footnotetext{
Un golpe en el rostro vuelve a tumbarle. En la manzana de Adán siente la presión que le hunde en el agua mientras Bazán le pega con un trozo de goma en la planta de los pies. Cuando creyó que se ahogaba con los pulmones reventados, el torturador lo emerge por unos segundos. Se acomoda sobre la tina y con las piernas comprime los genitales mientras Belotto lo sujeta de los cabellos debajo del agua. (Delvalle, 2012, p. 41)
}

Cuando pasamos al segundo capítulo, notamos que la obra describe el proceso de interrogación con menos enfoque en la represión física. No obstante, aparecen otras formas de la tortura como la del teléfono. Es una técnica de golpes en los oídos: "Le alzan para aturdirle con golpes en los oídos, una práctica conocida como "teléfono" (Delvalle, 2012, p. 100). 
Luego, se muestra otro tipo del terror que es la comida. Las autoridades representan intencionalmente una comida no válida para el consumo humano: "Mi orín, comenta Ramón Segovia, tendrá mejor gusto que esta porquería" (Delvalle, 2012, p. 99).

\subsubsection{Represión psicológica}

No todos los tipos de tortura aplicados por el gobierno son físicos, sino también hay otras formas psicológicas. A veces se usa la represión psicológica como un tipo directo de tortura y otras veces es una consecuencia de la represión física:

En su texto Contribución a la historia del movimiento psicoanalítico (1914), Freud afirma que la represión constituye uno de los conceptos esenciales sobre el cual descansa la elaboración teórica del psicoanálisis y asegura que la doctrina de la represión es una conquista del trabajo psicoanalítico, ganada de manera legítima como decantación teórica de innumerables experiencias. (Zapata, 2017, p. 63)

Aquí, Julieta María confirma que hay dos tipos de represión; represión física y psicológica. Además, se explica que la represión psicológica no solo influye a una persona, sino que a un grupo de gente o incluso a toda la sociedad.

El primer tipo de la represión psicológica está en el primer capítulo, en la celda Belotto (uno de los oficiales responsables de la tortura), donde se obliga a las víctimas a escuchar los gritos de los torturados en el proceso de interrogación mediante una grabadora:

De algún lado aparece Belotto arrastrando una silla que la ubica frente a la celda. Al sentarse, y ver que los presos le observan, hace funcionar la grabadora de donde salen gritos de los torturados. Cuando arrecian los tormentos, en su rostro se perfila una sonrisa de entero gozo. De vez en vez posa la mirada en algún detenido para señalarle con un gesto que el alarido es suyo. (Delvalle, 2012, p. 25)

Las celdas son siempre pequeñas y están llenas de presos que cuentan el terror que sufren durante la interrogación. Entonces, las víctimas en la pequeña celda esperando la tortura en cualquier momento: "Blas no puede dormir. Tiene la sensación de que le llevarán en sueño a la sala de torturas. Del susto se levanta al escuchar el ruido de la llave en la cerradura de la celda" (Delvalle, 2012, p. 24). 
Un claro ejemplo de la represión psicológica es Sucede, un estudiante de Derecho en la Universidad Nacional de Asunción. La policía lo arrestó por su participación en repartir panfletos y pintar paredes con leyendas alusivas a la dictadura. Luego, la policía le obligó a borrar las inscripciones con las uñas:

Cuando cayó preso, la policía le hizo borrar las inscripciones con las uñas. Después de haber estado cerca de cinco meses en Investigaciones, y de sufrir indecibles tormentos, una noche le tiraron en la casa materna de Barrerito, completamente desquiciado. Desde entonces, a cualquier acontecimiento responde con la frase que le dio identidad: lo que va a suceder sucede. (Delvalle, 2012, p. 149)

Una noche le tiraron en la casa materna de Barrerito completamente desquiciado. El gobierno quería mostrar a la sociedad ejemplos como el de Sucede con el fin de crear un miedo general y controlar la participación en cualquier actividad política. Las autoridades no solo pretenden reprimir los oponentes, sino también dominar a los demás.

\section{Situación social y religiosa}

Un viento negro aborda las nefastas consecuencias de la represión de la dictadura sobre la sociedad paraguaya. La novela describe las costumbres y los aspectos sociales en la época de la dictadura stronista.

\section{1 la vida social}

En la época stronista, la sociedad paraguaya se dividía en dos partes principales: la sociedad urbana y la rural. Cada una de ellas tenía sus propios aspectos y características.

\subsubsection{La sociedad urbana}

Las zonas urbanas se distinguen por tener mayor densidad de población y diversidad humana. Además, el estilo de vida en las zonas urbanas es de ritmo rápido. Por eso, se puede notar que las relaciones sociales entre las personas en Asunción están limitadas a la familia, los amigos y los vecinos. En el primer capítulo, el único contacto que tenía la señora Arzamendia el día de la caída de la dictadura para saber las noticias del golpe, era su hermana:

Al salir de la sala para regresar a la cocina le asusta el timbre del teléfono. Es la hermana que le invita a escuchar Radio Cáritas. Apaga el televisor y prende la radio. La noticia que da el locutor la deja tiesa. Nunca se había 
escuchado en los tiempos de la dictadura que los militares de la más alta graduación se alzaran contra el general Stroessner. (Delvalle, 2012, p. 1)

La obra muestra la estructura social paraguaya. El control de un grupo cercano al gobierno dictatorial sobre la industrialización nacional convierte la sociedad en Asunción en una sociedad burguesa:

En un país que apenas benefició de procesos de industrialización, con mínima clase obrera, con una burguesía altamente dependiente de los privilegios del poder político persisten las formas de las antiguas desigualdades de castas compitiendo con la difícil lectura en clave de clases sociales de la estructura social paraguaya. (Ortiz, 2016, p. 72)

La sociedad burguesa se caracteriza por la desigualdad entre las diferentes clases sociales. En el tercer capítulo, el testimonio de Ramón Segovia nos destaca la diferencia entre las clases sociales paraguayas según la descripción del complejo residencial de la fábrica:

Es parte de los tres niveles sociales con que la empresa divide a sus trabajadores. En la cúspide está el "chalet". Sus ocupantes, empleados superiores mayoritariamente extranjeros, disponen de pileta de natación, cancha de tenis, cancha de fútbol y un confortable hotel, escenario de las reuniones sociales y artísticas. Por último, entre los barrancos, viven los jornaleros en casillas de madera sin luz ni agua corriente. (Delvalle, 2012, p. 127)

En este ejemplo, se nota que el problema de la fábrica no es económico, sino que se aplica la desigualdad deliberadamente.

\subsubsection{La sociedad rural}

Al principio del segundo capítulo y a lo largo de los tres capítulos siguientes la obra trata de revelar los aspectos de la sociedad rural. Las zonas rurales se caracterizan por tener comunidades pequeñas muy unidas, y es frecuente que las personas que viven en áreas rurales se conozcan entre sí. Los campesinos son el núcleo de la sociedad rural y forman el sector más marginado por la dictadura. La sociedad rural se dispone de menor tecnología y la economía es menos desarrollada. Esta característica está descrita claramente en el tercer capítulo de la novela: “Cuando llegó con su esposa para quedarse, Ramón Segovia encontró un poblado constituido por unas 35 casas con paredes de estaqueo y barro, y techo de paja. Muy pocas, de ladrillo y techo de tejas" (V.N., p. 116117). También, aparecen todas las brechas negativas de educación, 
ingresos, salud, seguridad social, tipo de vivienda y condiciones de empleo. Luis Ortiz nos aclara que es una verdad historia:

Un reciente estudio del PNUD sobre desigualdades mostró que la dimensión socialmente más desigualadora en Paraguay de inicios del siglo XXI no era el sexo ni la geografía sino la lengua materna. La población guaraní parlante sigue acumulando todas las brechas negativas. (Ortiz, 2016, p.71)

El primer aspecto social de la sociedad rural en Un viento negro es la cohesión comunitaria y la unión de la comunidad. Se puede notar que esta es la característica más destacada en la obra. En el día de la caída de la dictadura se reúnen los vecinos y conocidos para ver la televisión y seguir las noticias del golpe militar: "Con la llegada de tres vecinos más, Dionisio traslada el televisor a la sombra de una enramada donde instala un banco y sillas. En las pausas comerciales comentan las noticias y hacen conjeturas" (Delvalle, 2012, p. 77-78).

En el cuarto capítulo, la obra nos narra la solidaridad de los campesinos, cuando la policía intenta arrestar a uno de los líderes de Las Ligas Agrarias Cristianas. El comisario local había recibido órdenes del Delegado de Gobierno para que busque de un dirigente liguero, Félix Montiel. El oficial, portador de la orden del comisario, interrumpió una reunión Las Ligas Agrarias y preguntó por Félix Montiel y en aquel momento todos los campesinos respondieron que son Félix para protegerlo:

El oficial, portador de la orden del comisario, interrumpe la reunión y pregunta por Félix Montiel.

-Qué quiere de él- pregunta el Padre Ferré

-El comisario desea conversar con él unos minutos

-Yo soy Félix Montiel -se levanta Raimundo Flores

-Yo también soy Félix Montiel -hace lo mismo un dirigente local Todos, de pie, dicen llamarse Félix Montiel. El oficial, al subir a la camioneta, les advierte que el desacato a la autoridad es un hecho grave. (Delvalle, 2012, p. 211-212)

Otro aspecto de la sociedad rural en Un viento negro es el orgullo del lenguaje guaraní. A lo largo de la novela, se nota que los campesinos insisten en hablar y aprender el guaraní a pesar de que el español es el idioma oficial del país. Este aspecto es una de las razones principales para establecer las escuelitas donde se enseñan las ciencias en guaraní en lugar del español. 


\subsection{Situación religiosa}

Las interrelaciones entre las instituciones religiosas, el estado y la sociedad son indispensables para conocer la significatividad de las creencias y los creyentes, en una determinada sociedad. La Iglesia forma parte fundamental de la historia paraguaya: "Ciertamente entre la aparición de una y otra obra se han publicado contribuciones que han destacado lo propio de la Iglesia como algo insoslayable, incluso principal, en el movimiento histórico paraguayo" (Salina, 2015).

La Iglesia paraguaya fue reprimida por su oposición a la dictadura y su apoyo al pueblo: "En cuanto a la afirmación de que Stroessner jamás tuvo enfrentamiento grave con la Iglesia, la realidad es otra. Su larga dictadura se colmó de violencia, verbal y física, contra sacerdotes y obispos, nacionales y extranjeros" (Delvalle, 2005).

Los campesinos son el grupo con más religiosidad. Así, la obra solo revela la situación religiosa de la sociedad rural. En Paraguay, sobresale el cristianismo en el plano de las creencias religiosas, destacándose el catolicismo como expresión mayoritaria. Entonces, la situación religiosa en Paraguay se basa en dos elementos generales: el papel de la Iglesia y el de los párrocos.

\subsection{El papel de la Iglesia}

La novela empieza la narración del papel de la iglesia con una realidad histórica. La Iglesia de Santa Rosa es una de las antiguas Iglesias en América Latina en general. La Iglesia fue establecida en el siglo XVII por las manos de los primeros jesuitas llagados de España. La obra menciona la historia propia de la iglesia porque a partir de una visión histórica de los vínculos entre la sociedad y la religión en Paraguay, estaremos en condiciones de discernir el alcance de la sociedad rural. El papel principal de la Iglesia es propagar la fe cristiana en la sociedad rural, sin embargo, la Iglesia de Santa Rosa tiene otras funciones. La iglesia está interesada por mejorar la vida social de los campesinos. Emplea sus instituciones y sus párrocos con el fin de desarrollar la sociedad rural y la enseñanza de los campesinos. 
La Iglesia no solo arroja la luz sobre la enseñanza religiosa de los campesinos, sino también sobre la enseñanza de diferentes ciencias sociales, políticas y económicas. Los campesinos solían reunir con sacerdotes no solo para comprender la Biblia, sino también para estudiar y comentar el texto de la Constitución Nacional.

La educación y la formación de los campesinos tienen como consecuencia el estabelecimiento de sus propios proyectos con el fin de impulsar el crecimiento institucional y económico, como el proyecto del almacén de consumo:

Cuando al cabo de un tiempo se sintieron sólidamente unidos, y buscaban impulsar el crecimiento institucional y económico, implementaron la idea de un almacén de consumo que desde hacía tiempo planeaba en las reuniones. La diferencia de precios en la compra-venta de los productos les hizo ver el tamaño del despojo que habían sufrido. (Delvalle, 2012, p. 50)

También se confirma que el concepto de la religión no se limita a ofrecer el reino de Dios a cambio de la pobreza y el sufrimiento a la tierra, sino que se extiende a garantizar la salud, la educación y la vida digna para los ciudadanos:

También procuraron que a todos les alcance el beneficio de un proyecto material impulsado por la misma iglesia que desde siempre les predicaba que para subir a los cielos hay que bendecir las penalidades de la pobreza. Ahora se les adoctrina en la idea de más producción y mejores ganancias. Se les dice que también en la tierra deben procurar un pedazo de cielo por el camino de la salud, la educación, vivienda digna, alimentación.” (Delvalle, 2012, p. 50)

\subsubsection{Los párrocos}

No hay mucha diferencia entre el papel de la Iglesia y el de los párrocos en la sociedad rural paraguaya, ambos comparten el mismo objetivo. Sin embargo, los párrocos muestran diligencias personales en el área del servicio de la comunidad.

Los párrocos en la novela están representados por el Padre Jacinto. El sacerdote es un jesuita español de 48 años. Es uno de los sacerdotes que trabajan con los campesinos en la capuera y en el templo. Antes de llegar a San Ignacio, estaba trabajando en otras comunidades misioneras con la misma tarea de promover el desarrollo material y espiritual de la población. El Padre Jacinto no solo orientaba a los campesinos en la 
doctrina cristiana, sino también les ayudaba a arar la tierra, cosechar, vender los productos. El padre quería estar conectado con todos sectores de la sociedad rural. Por eso, como muchos otros jesuitas, aprendió el guaraní para acercarse más a los hombres y las mujeres del campo.

El Padre Jacinto está muy querido en la comunidad por su trato amable y sus actividades con las Ligas Agrarias, a las que se incorporó con entusiasmo. Al mismo tiempo está muy odiado por la dictadura por la misma razón: "Se lo conoce como pa'i Juan. La dictadura le llamaba el "cura rojo" (Delvalle, 2012, p. 79). Sus ideas renovadoras, disposición para el diálogo y la firmeza de sus convicciones expresadas con mesura, se destacan en los congresos.

El sacerdote siempre acepta las críticas sobre sus opiniones y sus discursos religiosos. Ramón Segovia expresa su objeción sobre una parte del discurso del sacerdote: "Es cierto que está en la Biblia pero no me parece justo pedir que cumplamos las palabras de Jesús cuando dijo "Perdónalos porque no saben lo que hacen". Fue lo que dijo usted después de hablar de los torturadores. Éstos sabían muy bien lo que hacían" (V.N., p. 80). El Padre acepta el comentario de Ramón y le dice que tiene Razón.

En la noche de La Pascua, la policía secuestra al sacerdote de su dormitorio y lo conduce a Asunción. En el Departamento de Investigaciones se encuentra con otros seis jesuitas que también tienen relaciones con Las Ligas Agrarias Cristianas. Luego, los llevan a la ciudad fronteriza de Clorinda. Allí los dejan sin documentos y sin dinero con la advertencia de que nunca intentarán regresar a Paraguay:

En la noche de los apresamientos, la Policía secuestra al sacerdote de su dormitorio y lo conduce a Asunción para un breve trámite en el Departamento de Investigaciones de donde es llevado, al amanecer, a la ciudad fronteriza de Clorinda. Allí lo dejan sin documentos y sin dinero con la advertencia de que nunca intente regresar al Paraguay. Con el cura párroco de San Ignacio ya son siete los jesuitas expulsados por sus tareas en las Ligas Agrarias Cristianas. (V.N., p. 201)

Aquí el autor confirma que los párrocos fueron reprimidos como todo el pueblo por su situación política y su compromiso con los campesinos.

\section{Conclusiones}


En el presente estudio hemos planteado como objetivo principal analizar los aspectos de la vida social paraguaya en Un viento negro llegando a la conclusión de que se considera una novela testimonial. Uno de los motivos que nos impulsó a realizar este trabajo de investigación ha sido dar a conocer a la novela testimonial en América Latina en general y en Paraguay en particular. Por eso, hemos dedicado la parte teórica del trabajo para arrojar la luz sobre sus características, sus figuras más destacadas, su historia en América Latina y sobre todo su importante papel en la escena literaria actual en Paraguay.

Según nuestra investigación, se puede decir que el surgimiento de la novela testimonial en la literatura hispanoamericana se marca con la publicación de Biografía de un cimarrón (1966) del escritor cubano Miguel Barent.

Podemos decir que los acontecimientos críticos mencionados en $U n$ viento negro están confirmados por las diferentes referencias históricas. Según nuestra investigación observamos que el autor no solo utiliza las mismas acciones del acontecimiento real, La Pascua Dolorosa, sino también los mismos personajes, los mismos lugares y el mismo tiempo. La narración de la novela se mueve en dos tiempos principales: el tiempo de los acontecimientos en 1976 y el tiempo de la caída de la dictadura en 1989.

Por lo tanto, creemos que González Delvalle creó una novela testimonial con todos sus rasgos y características que le permitió reflejar los aspectos sociales e históricos de la vida paraguaya bajo la dictadura en general y las influencias psicológicas de la Pascua Dolorosa sobre la sociedad en particular. Después de haber investigado, podemos decir que Un viento negro es una de las primeras obras testimoniales de la literatura paraguaya.

La novela se concentra más en la sociedad rural porque los campesinos son los influidos por el tema principal de la novela, La Pascua Dolorosa. Como consecuencia del enfoque en la sociedad rural, se da importancia a la situación religiosa de la sociedad y al papel de la Iglesia en el desarrollo y la enseñanza de la comunidad campesina porque los campesinos forman el grupo más relacionado con la Iglesia en la 
sociedad paraguaya. Según Un viento negro, la Iglesia emplea todas sus habilidades para ayudarlos a mejorar su comunidad. El papel de la iglesia no se limita a los ritos religiosos, sino también le importa la ayuda de los campesinos en mejorar su comunidad económica y socialmente.

Finalmente, se puede decir que Un viento negro es una de las noveles más importantes para cualquier lector o investigador que pretende saber de una de las dictaduras más relevantes de América Latina, ya que es una obra testimonial con todos sus rasgos y características que nos traza los aspectos sociales e históricos de la vida paraguaya bajo dicha dictadura.

\section{Referencias}

Arditi, B. (1992). Adiós a Stroessner: La reconstrucción de la política en el Paraguay. Asunción: CDE.

Aseretto, R. M. (2001). Ligas Agrarias: Reseña de los orígenes, persecución y extinción de las Ligas Agrarias: Proceso judicial a los torturadores: Compilación. Asunción: CIPAE, Comité de Iglesias para Ayudas de Emergencia.

Barco, J. V. P. \& Alcalá, G. R. (1999). Narradoras paraguayas: antología. Asunción, Paraguay: Expolibro: SEP Libros Libres.

Calleja, E. G. (2006). Sobre el concepto de represión. Revista de Instituto de HistoriaCSIC, 6, 551-579.

Cardelli, J. (2016). La dictadura militar en la educación. Encuentro Saberes, 6, 13-22.

Contrera, J. (2018). La pascua dolorosa. Disponible en https://bit.ly/3blWDj9 (Fecha de consulta: 19/7/2019).

Dabéne, O. (2000). América Latina en el siglo XX. Madrid: Síntesis.

DelValle, A. G. (2012). Un viento negro. Asunción: Servilibro.

DelValle, A. G. (2005). La Iglesia Católica en los tiempos de Stroessner. Disponible en: http://bit.ly/3ntC1rG (Fecha de consulta 22/5/2019).

Faith, T. M. (1985). Paraguay: Novela y exilio. New Jersey: Slusa.

Gerbaudo, A. (2011). La lengua y la literatura en la escuela secundaria. Ciudad De México: Homo Sapiens Ediciones.

Gerendas, J. (1992). El fósforo cultivo: Literatura latinoamericana autodeterminación. Caracas: Universidad central de Venezuela.

Goicochea, A. (2000). El relato testimonial en la literatura argentina de fin de siglo. Tesis inédita. Universidad Nacional de Plata.

Lira, E. (2004). Consecuencias psicosociales de la represión política en América Latina. Barcelona: Icaria Editorial.

López, M. (2006). Características de la literatura testimonial, reflejadas en las obras la Terquedad del Izote Yluciéranagas en El Mozote. Tesis inédita. Universidad de Salvador.

Martínez, M. A., Castro, M. C., Rovira, D. P., \& Beristain, C. M. (2014). Paraguay: de las violaciones a los derechos humanos a la justicia transicional. Salud \& Sociedad, 5(1), 98-114.

Melo, D. (2009). El género testimonial en Hispanoamérica. En tres importantes novelas hispanoamericanas. San Juan: Textale. Disponible en https://bit.ly/2Xngruo. (Fecha de consulta 24/9/2017). 
Ortiz, L. (2106). Desigualdad y clases sociales estudios sobre la estructura social paraguaya. Asunción: CEADUC.

Salina, M. L. (2015). La escritura de la historia de la Iglesia en Paraguay: Algunos progresos recientes. Anuario de Historia de la Iglesia, 24, 97-115.

Telesca, I. (2014). Las ligas agrarias cristianas. Asunción: Editorial El lector.

Paz, A. B. (2014). El aparato represivo. Asunción: ABC Color.

Van Guyse, W. (2012). Una novela testimonial: Entre literatura y periodismo. Tesis doctoral). Universidad de Gante.

Zapata, J. M. (2017). Conceptos psicoanalíticos en discusión: El caso de la represión originaria. Perspectivas en Psicología: Revista de Psicología y Ciencias Afines, 14(2), 63-71. 